\title{
Wisdom of the Body in Sport and Exercise Practices
}

Authors' contribution:

A) conception and design of the study

B) acquisition of data

C) analysis and interpretation of data

D) manuscript preparation

E) obtaining funding

\section{Jernej Pisk}

St. Stanislav Institution, Slovenia

ABSTRACT

Two alternative ancient views on medicine and health can be distinguished in western antiquity: first, that the knowledge of the doctor is sufficient, and second, that health is primarily a consequence of adapting one's own life to the wisdom of the body. The body works according to its own laws, has its own "logic," and speaks its own language. Therefore, listening to the body can be an important source of information for a healthy human life. The body is not merely an object for human manipulation and "the prison of the soul," but a source of learning and knowledge. It seems that people rarely listen to their own bodies; however, the ancient wisdom of listening to the body is still present and cultivated in modern sports training. Good athletes and trainers are the ones who learn from the body and recognize its messages. In this article, we focus on four aspects of wisdom of the body, presented through four virtues: prudence, justice, fortitude, and temperance. The body teaches us temperance and justice; for example, when someone exaggerates too much, the body produces the feeling of pain. The body is a source of fortitude and persistence when rest and healing is needed. The body is a source of prudence or truth about oneself when we face the physical demands of sport. Therefore, through modern sports practices, the perennial wisdom of the body is still accessible to the modern man.

KEYWORDS body, wisdom, sport, cardinal virtues

\section{Introduction}

The phrase "wisdom of the body" might seem quite absurd at first. This is because wisdom is usually understood as a kind of metaphysical reality - something in our mind, not something that exists in the physical reality or is empirically sensible. Wisdom can be comprehended by reason alone. On the other hand, the body in its activities is not something thoughtful or conscious in and of itself. The body is experienced in and through our senses. Furthermore, the objective empirical science of medicine is widely recognized as the best approach for understanding the body and how it functions. However, the ancient Greeks have termed the embodiment or personification of "wisdom" Mētis, the daughter of Oceanus and Thetys. Among other things, she was the first love and wife of Zeus (Smith 1867). When considering human excellence, arête or virtue, Aristotle claimed that it was neither practical nor theoretical. As Miller (2004, p. 239) states, Aristotle's belief was that "all parts of the human person - body, soul and mind - were needed to practice arête." This demonstrates with clarity why Aristotle saw physical education as essential in supporting the development of knowledge: 
"Education must clearly use habit as an instrument before theory, and the education of the body must precede that of the mind" (Aristotle 1338b). That is why Miller wrote in his Ancient Greek Athletics "The academy of Plato was first and foremost a place of exercise for the body" (Miller 2004, p. 240).

When discussing the body and knowledge, it is possible to recognize two different models from ancient times: the first views the body as a source of knowledge, and the second views it as only the object of knowledge. The transfer from the first perspective to the second happened during the Renaissance period. The line between them was drawn in the essays of Montaigne (Collier 1998). While in the first model the body is the source of knowledge of oneself, the second represents the medical practices of the time, especially anatomy, where the body was viewed as an object to be scrutinized in research in order to support advancement and increase in knowledge. Thus the role of the body was transformed from being the source of knowledge to the object of the mechanical sciences, rendering it unable to recognize its own messages and inherent wisdom any longer. Unfortunately, with this the body became limited to an object of cognition, meaning that the ancient wisdom of listening to the body was lost. When this happened, the idea of the "wisdom of the body" became nonsense. However, in ancient times as well as in modern times, the most happy and fulfilled human beings have been those who maintain a harmonious relationship with their bodies. It seems that the practice of listening to the body has been better preserved in the East than in the West. In their book Listening to Your Body: The Wisdom of the Dao, Guo and Powell (2002, p. 30) wrote: "The body has a mind of its own and the art is learning how to listen to what it is saying. Every symptom is a communication, alerting us to an underlying imbalance." In the West, two different (ancient) understandings of medicine can be identified that go hand in hand with the above models about the relationship between the body and knowledge. For the first one, health is the consequence of a harmonious life in accordance with nature, and therefore the cognition of oneself and one's own nature is very important. This is seen as the normal way to attain a healthy life. The other account of medicine suggests that doctors' knowledge and the sharp knife of a surgeon is all that is needed to resolve any health problems. This is why "in ancient Greece, doctors worked under the patronage of Asklepios, the god of medicine, while healers served Asklepios's daughter Hygeia, goddess of health" (Collier 1998). Doctors search for the proper medicine and techniques for their patients, but for healers, health is primarily the consequence of harmony in the body and harmony between the body and the whole cosmos. Therefore, for healers, the first thing to do is to teach people how to listen to their bodies and to the world around them. There is a well-known example of Herodicus that is mentioned in Plato's Republic. He was very successful in using bodily exercises for the preservation of his health so "he won the prize of a doting old age" (Plato 406b).

On the topic of Plato, we must mention his perspective on the body. "Do not believe that a sound body by its excellence makes the soul good, but on the contrary that a good soul by its virtue renders the body the best that is possible," he urged (Plato 403d). In this case, the body is understood as an object subordinate to the soul, which guides the actions of the body. However, Plato himself recognized the power of the body in shaping the soul: bodily exercises can help in the education of the soul (Plato 410a-411a). This is similar to what modern psychophysiology has discovered: "Every change in the physiological state is accompanied by an appropriate change in the mental emotional state, conscious or unconscious, and conversely, every change in the mental emotional state, conscious or unconscious, is accompanied by an appropriate change in the physiological state" (Green, Green \& Walters 1970, p. 3 in Bar-Eli 2002, p. 2). We can see that if the soul ${ }^{1}$ is open to the messages of the body, the body can contribute to the development of the whole human being. Nonetheless, this was the reason that Plato included physical exercises within his community for teaching and learning. The knowledge associated with the wisdom of the body or "the logic of the body," which is the way the body works, is a prerequisite for any physical educator, trainer, or coach. They must listen to the body and respond to the messages it is giving out. It is true that in the modern process of sports training the messages of the body can be partly grasped via empirical measurements like heart rate, blood lactate concentration, hormone response, etc. Despite this, top-level coaches and trainers acknowledge that elite sport training is not

\footnotetext{
${ }^{1}$ We use the term "soul" in a broad sense, including "mind," "spirit," and/or "consciousness."
} 
just a science but also an art. The body does not function like a machine, and therefore precise physiological and biomechanical measurements cannot reveal all variables that influence physical performance. The essence of training is the ability to recognize the messages of the body. To feel and understand what is going on in one's own body is one of the most important abilities of a well-educated athlete. Good trainers can help athletes gain this ability (Lydiard 1997, p. 40). We can go a step further and say that to listen to the body means to listen to its "music." Namely, the body is working in rhythm: the rhythm of the heart, rhythm of the breath, rhythm of our strides while we are running, etc. Experienced runners know very well the harmony between their breathing and their strides. This harmony allows them to run as fast and as economically as possible. For example, the 1-4 rhythm is very common: inhalation, four strides, exhalation, four strides, etc. If the harmony of the rhythm is disrupted, then motion becomes more tiresome. The modern theory of sports training uses many ideas and concepts that have been derived from the experiences of body, which signal its wisdom. They are based on recognitions of bodily messages in different situations. This part of sport science is known as the cyclization of training. The origins of this can be found in ancient Greece, where the so called "tethrad system" of training was well known. We will address this in more detail later in the article.

Let us return to the first question: is the body the source of knowledge or just an object of knowledge? Is the body something that teaches us or just something that we can learn about? Our further investigation will try to call attention to different kinds of body messages in sport and recognize the inherent wisdom of the body in them. Ancient and modern cognitions from sport training and body culture (Kosiewicz 2010, p. 23) will help us in this task. We acknowledge that a discussion about what wisdom really is could be endless. There are many different options based on different philosophical or religious traditions. For our purpose, we will lean on the four cardinal virtues (prudence, justice, fortitude, and temperance), which are classically understood and used for defining human wisdom as the harmony between human capacities, intentional acts, and the external world. These four virtues can be found across different philosophical systems and religious traditions. ${ }^{2}$ When they are developed and practiced by the human individual, they lead to the fulfillment of human capacities and the flourishing of human life. Thus these types of virtues have been defined as "ultimum potentiae" (Aquinas I-II, 55, 1), and therefore they are a kind of incarnation of wisdom in the human being.

\section{Prudence of the body}

Let's start with the virtue of prudence - or as it is sometimes called, the virtue of wisdom. Prudence "gives birth" to all moral virtues (Pieper 1949, p. 6). It is often characterized as intelligence. But what kind of intelligence does the body have? What is the prudence of the body? Prudence as a virtue is characterized by two faculties. First, prudence is directed towards the knowledge of truth, objective reality itself; second, it gives instructions for action. Prudence can be learned from the actions of the body itself. Knowledge-incurring activities can be facilitated by the body and not only through pure reason. This can be recognized in the origins of western culture. Bodily physical activities (like sports), philosophy (the shared human struggle for truth), and democracy (as a political system) all have the same birth place: ancient Greece. The oldest among them is sport or ancient athletics, which started no later than in $776 \mathrm{BC}$ with the first Olympic Games. Philosophy began later, in the sixth century BC, followed by democracy. As Heather Reid (2012, p. 3) claims, the crucial factor in the development of ancient Greek culture was the rise of athletic competition because these competitions helped question the "natural" social hierarchies and "natural" aristocracy governing the social system of that time. It was shown that athletes with a non-aristocratic background could gain bodily perfection. Therefore, the body was constituted as an element of truth or revelation: contests in sport always dismiss any doubt about who is the fastest, strongest, or most skilled. Thus it is clear why Pindar in his Olympic Odes nicknamed ancient Olympia, the place where sport competitions were held, the "Mistress of Truth" (Pindar 2005 , p. 205). The body is not concerned about the supposed aristocratic origin of some people. This is the

${ }^{2}$ They can be found in Plato (Republic, 427e), Aishiles (Sept. 610 in W. Jaeger [1973, p. 106]), in Pindar's Odes (Isthemian Od 8, 24-28), and in the Old Testament of the Bible in the Wisdom of Solomon: "And if anyone loves righteousness, her labors are virtues; for she teaches temperance and prudence, justice and courage; nothing in life is more profitable for mortals than these" (Wis 8, 7). 
true value of the body: it puts in front of us a mirror of ourselves and our abilities. Our body forces us to face the real truth of our capabilities, despite all our attempts to overlook them. It could be said that some form of superficial and momentary avoidance of these truths can be obtained through the use of anti-pain medicines (Corlett 1996). When the body showed that the supposed aristocratic origin of some people was not something fixed, it provided Socrates, Plato, and Aristotle with the stimulation required to pursue their educational work (Reid 2012, p. 4). Thus the wisdom of the body obtained in sporting pursuits questioned the pre-existing social hierarchy.

Besides this, human bodily activities can be a fruitful entrance into authentic living - one of the central concepts of existentialism and post-modernism. Because of the physical body, physical laws in sport cannot be as easily dismissed as the laws associated with mental activities can. The statement that it is possible to "build castles in the air" contradicts reality, but not in sport. Namely, when we force our physical body beyond its capabilities, it starts to hurt and could even sustain injury. We must acknowledge that children are wiser than adults in this regard because they are usually not so inclined to overestimate their own limits. When they begin to feel pain, they stop. When the pain stops, they start running again. This is the way in which bodily activities force modern man to have contact with his own physical reality. It also enables him to go beyond mere theoretical or institutionalized doctrines about the human being and his nature, which often have a strong influence on human society. These are artificial and often in conflict with reality; therefore, sooner or later, they lead to destruction. This is the point where Leo Strauss (1965, p. 119) recognized the problem of modernity: "In the modern era the notion that nature is the standard was abandoned." When modern man abandoned nature as the standard, the nature as Logos, which served as a support for ethics and for direction towards human fulfillment, he found himself in front of a vacuum. Therefore, other systems and fictitious theories often fill this empty space.

A common obstacle for listening to the wisdom of the body is the old but strong dualism between the body and soul. This dualism is shown in different ways that separate the conscious self and the body. Sometimes it is possible to recognize this in cases when listening to music is combined with bodily practices and when our own conscious mind is "switched off" while the body continues to work. Today, this is a frequent practice that makes the gap between the body and soul seem even deeper. Cases like this are led by a very pragmatic and instrumental understanding of sports practices, when a person "uses" sport to gain or preserve bodily health or physical fitness while trying to protect his or her soul (mind) from the feeling of pain or fatigue. Therefore, the soul (mind) must be directed in other ways and towards other things at the same time. Reid rightfully introduced the term "philosophical athlete" into the field of sport philosophy. This is an athlete that

"focuses on the intrinsic rewards of sport such as self-knowledge, ethical virtue, and learning to work with others as part of a team... The philosophical athlete knows that the greatest opponent is the self, the greatest challenge personal excellence, and the greatest reward true happiness" (Reid 2002, p. xiii).

These are infinite rewards, while external rewards such as the gold medal, money, or even health are only temporal.

In the above discussion, we focused on some points where listening to the body can contribute to the knowledge of truth. The second form of prudence is in giving instructions for action. This kind of wisdom can be found in the proper cyclization of sport training: the body's work (catabolic phase) and rest (anabolic phase) must be properly adjusted.

\section{Justice of the body}

An essential characteristic of justice is to give someone their due. "To be just means, then, to owe something and to pay the debt" (Pieper 1965, p. 57). But what can our body teach us? What kind of justice? What belongs to the body in such a way that the soul could owe it? First of all, the body teaches us the law of the conservation of energy (the first law of thermodynamics). If we are expecting that the body will work, we have to provide it with enough energy. Food, drink, and rest belong to the body as an object of justice, a thing 
owed by a person to his or her body. If this justice is not fulfilled, then the body will respond with different degrees of pain, illness and injury, and finally, with death. Pain, illness, or injury are the body's messages that we owe something to it.

In the process of sport training, coaches deal with the body's responses to the training load. This part of sport training theory is known as the "cyclization of training." Cyclization defines the frequency, intensity, and duration of workouts. Careful attention to the response of the body is needed during and after a workout. In this sense, cyclization is nothing but carefully listening to the wisdom of the body and acting in accordance with it. This is the essence of justice: to give the body what it is owed. For success in training, the body demands an alternation between easy and hard workouts, easy and hard days of training, and easy and hard weeks of training regarding the intensity, frequency, and volume of work done. This is the body's own protection against injury or overtraining. The justice of the body demands proper regeneration and rest between workouts. Even in ancient times, they knew of the so called "tetrad system" of training. Philostratos (born in 170) wrote:

By the tetrad system we mean a cycle of four days, each one of which is devoted to a different activity. The first day prepares the athlete; the second is an all-out trial; the third is relaxation; and the fourth is a medium-hard workout (Sweet 1987, p. 225).

This was the way coaches in ancient times tried to recognize and follow the natural rhythm of the body and justly fulfill its demands.

\section{Fortitude of the body}

The virtue of fortitude is displayed in two forms: as endurance and as the courage to attack (Pieper 1965, p. 126). The wisdom of the body that is of interest here is primarily displayed through endurance. The other kind of fortitude is the courage to attack, which is primarily a virtue of reason. Plato (194d) stated that "courage is a kind of wisdom." For him, "the wisdom that knows what is and what is not dreadful, is courage" (Plato 1967, 360d). But to endure and be patient are qualities that the body can also teach us. Plato himself highly praised physical exercise, so much so that he included it in his educational system. The reason for this was the influence of bodily exercises for the development of the soul, particularly the virtue of fortitude (Plato 1969, pp. 410-412; 190c). Thus, the body is the one that teaches the soul its wisdom. Therefore, an educated man will undertake exercises and the toils of gymnastics "with a view to the spirited part of his nature to arouse that rather than for mere strength, unlike ordinary athletes, who treat diet and exercise only as a means to muscle" (Plato 410b). Therefore, athletes have only partial benefit from physical exercises, for it is true that "gymnastics, I take it, is devoted to that which grows and perishes; for it presides over the growth and decay of the body" (Plato 521e).

The body teaches us to be patient and to endure, as it is not possible to gain any improvement in bodily performance in an instant. The process of training and developing the body need time and effort. Injury can occur in an instant, but the body teaches us to be patient and wait, as time is needed for healing. As we saw in the discussion of the cyclization of training, time is needed to allow the body to rest between workouts, especially when athletes try to moderate their performance. They must usually decrease the quantity and intensity of workouts before an important race. No matter the reason, the body needs time to rest, and this cannot be ignored. We can conclude that the body teaches us how to live in accordance with the rhythm of nature, which cannot be changed by force.

\section{Temperance of the body}

Temperance is the last among the cardinal virtues, but the one that the body is constantly teaching us about. For ancient philosophers, the idea of the golden mean and moderation is a central one. The functioning of the body was one of the most important sources for this idea: whenever we try to exaggerate too much or too little during bodily exercises, the body warns us with pain or even with injury. Therefore, since ancient times bodily exercises have been a great means for not only the development of the virtue of fortitude, but also the virtue of temperance. In antiquity, athletes were called asketés. Asceticism, which is derived from the Greek word áskesis, referred originally to the sort of exercise, practice, or training in which athletes engage 
(Quinn 1998). They were exercising to overcome "small pain" in order to gain a great reward (Aristotle 1934, 1115b). Dio Chrysostomos, who lived in the first and second century AD, wrote about special virtues that athletes must have:

The most amazing thing about the man was that he was not only superior to his opponents but also overcame fatigue and blazing heat and the urging of his stomach and his sexual drives. For the man who intends not to yield to an opponent must first not yield to these (Sweet 1987, p. 76).

Controlling one's own bodily needs and sensations is the first step to winning against the opponent. The body teaches the athlete how to govern the self - how to be temperate. There are many other examples from the history of athletics where temperance was emphasized. Plato wrote about it in his Laws:

Have we not heard reports about Ikkos, citizen of Tarentum, because of his victory at Olympia in pentathlon in 444 BC and other games? As the story goes, because of his desire to win, his ability, and courage in his heart along with self-control, he never touched a woman, or a boy either, in the entire course of his training. The same story exists about Krison, Astylos, Dipompos, and many others (Plato 839e-840a).

The wish to become an Olympic champion demanded a lot from athletes. The athletes had to give themselves up to the instructions of the coach, just as they did to the instructions of the doctor. Epictetus wrote:

You will have to obey instructions, eat according to regulations, keep away from desserts, exercise on a fixed schedule at definite hours, in both heat and cold; you must not drink cold water nor can you have a drink of wine whenever you want. (...) And after all that there are times when you lose (Sweet 1987, p. 114).

Obviously, the training of athletes demands various kinds of restrictions and self-denial, but it is always for the purpose of competing in order to win. This is a worthy price to be paid. Dio Chrysostomos wrote:

"You spoke about the pleasures he [the athlete] has missed. Whoever enjoyed more pleasure than

an athlete eager to win who was always victorious and who knew that he was an object of admiration?" (Sweet 1987, p. 76).

Even today, it seems that the body has the special power to bring modern man to moderation whilst other means, like preaching or arguing, simply do not. The body has its own demands that cannot be denied. As a rational being, humans can partly overcome the limitations of the body, but in the end the body always brings us back down to earth, to reality itself. Dualistic ideas about the separation of body and soul have always been very powerful in philosophy and religion; nevertheless, the body has always proved its irrepressible role in the holistic education of human beings. This is because the "golden mean" or "moderation" is associated with the essence of the body itself. Everybody has experienced how too much or too little food, drink, or rest can cause a strong reaction from the body in the form of pain, illness, or injury. Pain is the body's own response to too much or too little of something. In his Republic, Plato criticized people who considered themselves as educated but because of their immoderate lifestyle needed a doctor (Plato 405a). They did not listen to the wisdom of the body. The body has its own wisdom, its own logic that cannot be denied in the long run. Pain occurs when we go beyond the limits of our own comfort.

The purpose of temperance is to gain inner order and harmony. This is the key principle for the normal functioning of the body. The following is needed in order to live within the stable and harmonious order of different subsystems: the concentrations of different substances in the blood, the temperature of the body, blood pressure, etc. If anything deviates from normal values, we become ill and could even die. The principle that helps the body to attain inner harmony is called homoeostasis. The word was first used by Walter Cannon in the year 1929, and later in his 1932 book The Wisdom of the Body (Siegel 2008, p. 242). Homoeostasis is the response of the body to changes in the environment for the purpose of attaining balance. This part of the wisdom of the body is crucial for human health as well as for sports training. The aim of any sports training program is to destruct the homoeostasis of the body (achieved through workouts), triggering the body's own tendency to reinstate its natural balance. In other words, the body adapts to the workout. The alternation between the catabolic phase (the effort involved in the workout) and the anabolic phase (rest) leads to the so- 
called "supercompensation" of inner homoeostasis, meaning that the capacity of the body to tolerate increased intensity improves.

However, we must acknowledge that bodily sport activities not only cultivate the wisdom of the "golden mean," but may also lead to excess. For many athletes, as well as for fans of sport, this is the place of delight and pleasures. Pleasures attract people, causing a form of addiction to sport. And thus sport can take control over a human being. This is not necessarily rare on an individual or group basis; even in ancient Rome, the slogan "panem et circenses" was well known and used by the government. However, similar attitudes towards sport can be recognized in modern times. The problem is when the state takes control over relations between human beings and sport, allowing them to manipulate people (Vodeb 1998, p. 1105). The state then begins to support and promote sports activities to preserve its authority and power over its citizens. Therefore, listening to the wisdom of the body, which tries to teach us temperance and self-control, is important.

Finally, we must acknowledge that temperance is not the final aim of human living. From ancient times to the present, temperance has been a means to attaining higher ends, such as those associated with the knowledge of truth and happiness. Therefore, temperance has not only been connected to desires and pleasures, but also to the question of human knowledge. Aquinas once pointed out that a disordered human life regarding food, drink, and sex influences the human capability to know the truth. If any human desires to become disordered, then he or she starts to desire what is bad, mistakenly thinking that it is good (Cates 2002, p. 323). This is why Aquinas warns that disordered pleasures can "dim the light of reason from which all the clarity and beauty of virtue arises: wherefore these pleasures are described as being most slavish" (Aquinas II-II, 142, 4). This can be seen across all the varying forms of addiction. Therefore, the temperance that the body teaches us can support the holistic education of human beings and help them in their universal pursuit for the knowledge of truth.

\section{Conclusion}

We have seen that the body has its own laws, its own "logic," and its own "wisdom." The body teaches us prudence. This can be recognized in the cognition of truth about the self and in our own capabilities. The body teaches us justice: it warns us to give it what it deserves. It teaches us fortitude or courage: a lot of patience is needed because healing and rest takes time; this is something that cannot be overlooked. The body teaches us temperance because it responds with pain or injury in the event of any exaggeration. The principles that are at work in the body are not something strange, but rather are our own, because we are our bodies. The body is the physical nature within us. It is the medium through which nature presents its logos, its wisdom, to us. To live according to our physical nature has been the essence of wisdom since ancient times. It could be suggested that this is even more important today, in the time of information technology with its virtual realities, a time when we are often more disconnected from our own physical nature than ever before. This information doesn't hurt as our body can hurt. Such information doesn't halt us when we exaggerate, as only the body can. The body provides us with physical measurements about the good and the bad. As Leo Strauss (1965) suggested, nature is a measure. The issues that have arisen in modern morality have their origins in the separation of modern man from nature. Similarly, Friedrich Nietzsche (1921) critically emphasized that the negation of the body is the paradigmatic model of modernity. Therefore, to recognize the voice of the body and live according to its wisdom can be the first step towards authentic living. As in antiquity, sport and exercise practices are given a privileged place in modern times because they can communicate the wisdom of the body.

\section{REFERENCES}

Aquinas, T. (1947). The Summa Theologica. Benziger Bros. Retrieved May 25, 2017, from http://hspriory.org/thomas/summa/FS/FS055.html.

Aristotle (1934). Nicomachean Ethics. Aristotle in 23 Volumes, Vol. 19. Cambridge, MA: Harvard University Press. Retrieved March 29, 2017, from http://www.perseus.tufts.edu/hopper/.

Aristotle (1944). Politics. Aristotle in 23 Volumes, Vol. 21. Cambridge, MA: Harvard University Press. Retrieved February 12, 2017, from http://www.perseus.tufts.edu/hopper/. 
Bar-Eli, M. (2002). Biofeedback as applied psychophysiology in sport and exercise: Conceptual principles for research and practice. In B. Boris, M. Bar-Eli, \& G. Tenenbaum (Eds.), Brain and Body in Sport and Exercise: Biofeedback Applications in Performance Enhancement (pp. 1-14). Chichester: John Wiley \& Sons.

Cates, F.D. (2002). The virtue of temperance. In J.S. Pope (Ed.), The Ethics of Aquinas (pp. 321-39). Washington, D.C.: Georgetown University Press.

Collier, C. (1998). The Body as Teacher: From Source of Knowledge to Object of Knowledge. The Paideia Project OnLine. Retrieved May 25, 2017, from https:/www.bu.edu/wcp/Papers/Anth/AnthColl.htm.

Corlett, J. (1996). Sophistry, Socrates, and sport psychology. The Sport Psychologist, 10(1), 84-94. https://doi.org/10.1123/tsp.10.1.84

Green, E., Green, A.M., \& Walters, E.D. (1970). Voluntary control of internal states: Psychological and physiological. Journal of Transpersonal Psychology, 2, 1-26.

Guo, B. \& Powell, A. (2002). Listen to Your Body: The Wisdom of the Dao. Honolulu, HI: University of Hawai'i Press. Jaeger, W. (1973). Paideia: The Ideals of Greek Culture. Vol. 1. Oxford: Oxford University Press.

Kosiewicz, J. (2010). Social and biological context of physical culture and sport. Physical Culture and Sport. Studies and Research, 50(1), 5-31. DOI: 10.2478/v10141-010-0021-1

Lydiard, A. (1997). Running to the Top. Aachen: Meyer \& Meyer Verlag.

Miller, S.G. (2004). Ancient Greek Athletics. New Haven, CT: Yale University Press.

Nietzsche, F. (1921). Thus Spake Zarathustra. New York, NY: Boni \& Liveright Publisher.

Pieper, J. (1949). On the Christian idea of man. The Review of Politics, 11(1), 3-16.

Pieper, J. (1965). The Four Cardinal Virtues. New York, NY: Brace \& World, Inc.

Pindar (2005). Pindar's Songs for Young Athletes of Aigina. New York, NY: Oxford University Press.

Plato (1955). Laches. Plato in Twelve Volumes, Vol. 8. Cambridge, MA: Harvard University Press. Retrieved November 1, 2016, from http://www.perseus.tufts.edu/hopper/.

Plato (1967, 1968). Laws. Plato in Twelve Volumes, Vols. 10 \& 11. Cambridge, MA: Harvard University Press. Retrieved May 25, 2017, from http://www.perseus.tufts.edu/hopper/.

Plato (1967). Protagoras. Plato in Twelve Volumes, Vol. 3. Cambridge, MA: Harvard University Press. Retrieved May 25, 2017, from http://www.perseus.tufts.edu/hopper/.

Plato (1969). Republic. Plato in Twelve Volumes, Vols. 5 \& 6. Cambridge, MA: Harvard University Press. Retrieved May 25, 2017, from http://www.perseus.tufts.edu/hopper/

Quinn, L.P. (1998). Asceticism. In Routledge Encyclopedia of Philosophy. CD-ROM edition. DOI: 10.4324/9780415249126-L006-1

Reid, L.H. (2002). The Philosophical Athlete. Durham, NC: Carolina Academic Press.

Reid, L.H. (2012). Introduction to the Philosophy of Sport. Plymouth, MA: Rowman \& Littlefield Publishers.

Siegel, S. (2008). Learning and the wisdom of the body. Learning \& Behaviour, 36, 242-252.

Smith, W. (1867). A Dictionary of Greek and Roman Biography and Mythology. Boston, MA: Little, Brown and Company. Retrieved November 1, 2016, from http://name.umdl.umich.edu/ACL3129.0001.001.

Strauss, L. (1965). Natural Right and History. Chicago, IL: The University of Chicago Press.

Sweet, E.W. (1987). Sport and Recrseation in Ancient Greece. Oxford: Oxford University Press.

Vodeb, R. (1998). Ideološke paradigme v športu /Ideological paradigms in sport/. Teorija in praksa, 35(6), $1100-1117$.

AUTHOR'S ADDRESS: $\quad$ Jernej Pisk

St. Stanislav Institution

Štula 23, 1210 Ljubljna-Šentvid, Slovenia

E-mail: jernej.pisk@gmail.com

Received: 10 April 2017; Accepted: 3 June 2017 